\title{
Numerical and Experimental Stress-Strain Analysis of a Rubber Carousel
}

\author{
Peter Koščák ${ }^{1}$, Lubomír Ambriško ${ }^{2}$, Karol Semrád ${ }^{1}$, \\ Daniela Marasová, Jr. ${ }^{2}$, Vladimír Mitrík ${ }^{2}$ \\ ${ }^{1}$ Faculty of Aeronautics, Technical University of Košice, Rampová 7, 04121 Košice, Slovak Republic \\ ${ }^{2}$ Faculty of Mining, Ecology, Process Control and Geotechnologies, Technical University of Košice, \\ Letná 1/9, 04200 Košice, Slovak Republic
}

\begin{abstract}
The effect of the impact load exerted by the baggage impacting light baggage carousels may be manifested as mechanical damage to the carousel as a result of the stress-strain processes. In order to describe the phenomena related to the baggage impact, it is important to monitor the tensile strength of rubber carousels of light conveyor belts intended for the conveyance of baggage at airports. The output of the article is monitoring the mechanical load of the carousel, the comparison of the results thereof with the outputs of the CAE analysis, as well as the determination of the optimal material model and the approximation thereof to the experimental model.
\end{abstract}

Keywords - carousel of conveyor belt, modelling, regression model, CAE analysis, material model

\section{Introduction}

The quality of individual logistic and technical systems used at airports largely affects the air traffic. Airline companies, and consequently also passengers, expect and perceive handling with baggage and goods to be the key component of the airport services.

DOI: 10.18421/TEM104-23

https://doi.org/10.18421/TEM104-23

Corresponding author: L'ubomír Ambriško,

Faculty of Mining, Ecology, Process Control and Geotechnologies, Technical University of Košice, Letná 1/9, 04200 Košice, Slovak Republic.

Email: lubomir.ambrisko@tuke.sk

Received: 08 May 2021.

Revised: 22 September 2021.

Accepted: 30 September 2021.

Published: 26 November 2021.

(cc) BY-NC-ND (C) 2021 Peter Koščák et al; published by UIKTEN. This work is licensed under the Creative Commons Attribution-NonCommercial-NoDerivs 4.0 License.

The article is published with Open Access at www.temjournal.com
Baggage handling systems (BHS) at airports are very important for achieving satisfaction among passengers [1].

The increasing intensity of the competition in the air transport segment induces continuous pressures demanding improvements in the whole baggage manipulation process. Over the past years, there has been a fast progress in the global economy; as a result, the transport of baggage is as fast as a flight. Baggage handling systems must meet strict requirements and be reliable. The impact of the human factor on the process of baggage collection at the required place and time represents an important aspect of providing satisfactory services to air passengers [2].

Due to the highly technical nature of these systems, it is necessary to address the technological aspects of the entire process chain and prevent thus the formation of problematic points while balancing the peak times to the maximum extent. Bart [3] describes an assignment problem occurring at airports. This problem concerns the assignment of baggage carousels in baggage claim halls to arriving aircraft (baggage carousel assignment problem). This is a highly dynamic problem since disruptions frequently occur during operations.

The dynamic impact process, running as the load and baggage impact a conveyor belt, causes the wear [4] and the failure of basic physical and mechanical properties of conveyor belts. Statistical processing of the results of measurements of impact resistance within the testing of various types of conveyor belts, based on regression models, is presented in papers [5], [6]. Authors Marasová and Ambriško [7], Bindzár and Grinčová [8] analysed the processes occurring at the impact site as well as the formed stress and strain, using the mathematical modelling. The conveyor belt impact process and damage were investigated by a number of authors [5], [9], [10].

The most frequently observed types of damage to composites made of rubber and gum are cracks. The presented study by authors [11] investigated the fatigue life of composites made of natural rubber and 
related damage mechanisms. The fatigue analyses are currently carried out using the technology that facilitates predicting how fast a crack would grow through a component, instead of a more limited ability to predict the time to failure. The crack growing process, underlying all types of fatigue damage, is a very complex phenomenon [12]. The failure analysis and prediction of fatigue life are very important in the designing process as they contribute to ensuring safety and reliability of rubber carousels. Many experts conducted investigations of the fatigue life of rubber components. Long et al. [13] developed a new testing device intended for the identification of the fatigue life of elastomer materials as well as the biaxial fatigue life. Dai et al. [14] analysed the cracks and monitored the propagation thereof. Wang and $\mathrm{Lu}$ [15] investigated the static and elastic nature on the basis of the FEA, using the FEA ABAQUS and ADINA software products.

According to [16] sufficiently accurate modelling of rubber behaviour still remains an open question. The properties of rubber are rather varied, depending on the rubber composition and the contents of special additives [17].

Authors Zhang and Zhao [18] summarized the research status of mechanics experiment of rubber materials under dynamic and static load and commented on the recent years of domestic and foreign progress in the field of rubber uniaxial and multiaxial fatigue.

The paper [19] discusses the monitoring of load conditions applied during the tests of fatigue life of rubber products. The research began with the investigation of the effects of a higher frequency $(5 \mathrm{~Hz})$ compared to the frequency relevant for the particular product $(1 \mathrm{~Hz})$. The research results confirmed that higher frequencies do not affect the fatigue life; however, they definitely affect the specimen temperature and material behaviour.

Mechanical properties of rubber materials are complex and the issues regarding their strength have been more and more studied. The problems accompanying rubber materials, their models, and modelling their behaviour have been examined by several authors in various structures and conditions [20], [21], [22].

The purpose of the present article is the experimental and numerical analysis of stress and strain induced by the dynamic force in a rubber carousel at the impact of the baggage. A carousel failure may cause the failure of the whole conveyor. An important structural component, in addition to the carousel, is also the Ball Transfer Unit. Authors Mapelli and Barella [23] investigated reliable identification of the causes of the loss of the rotational attitude which represents the main functional property of this mechanical bearing component. Visual inspections, microscopic analyses (optical and SEM), and computational simulation have been carried out to understand the failure mechanism [23].

The presented work is an analysis of qualitative properties of rubber carousel as an element of system of elimination of safety risks and promotion of public health in airport operations.

\section{Materials and Methods}

\subsection{Problem Formulation}

The impact of the baggage on a conveyor belt often induces the stress-strain processes in rubber carousels, changes in physical and mechanical properties of the rubber carousel, as well as the damage and wear thereof. The damage occurs mainly on the surface of carousels and the wear occurs mainly on their top layers (Figure 1.). This type of damage occurs when a carousel absorbs the energy of the baggage impact. The wear of the lower layer of the carousel is lower.

The article presents the stress-strain analysis performed within the experimental testing of physical and mechanical properties of rubber carousels. The analysis results were subsequently transformed for the purpose of the CAE analysis.

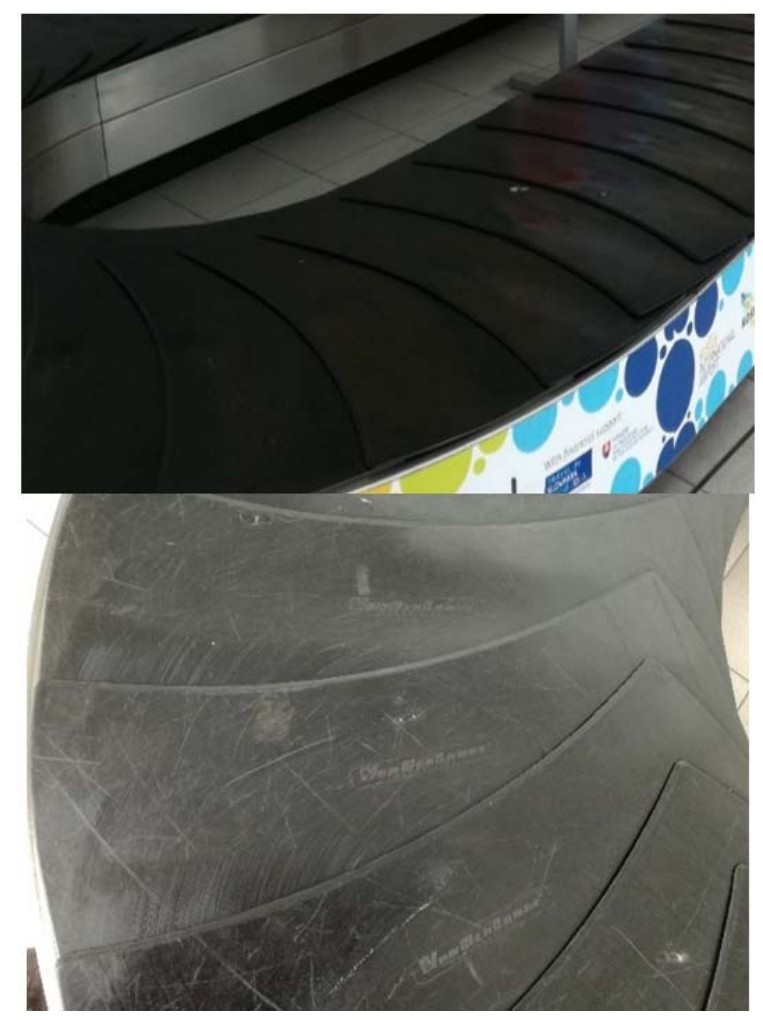

Figure 1. Damage to rubber carousels during the baggage conveyance at the airport 


\subsection{Description of the Experiment and Methods}

The stress-strain processes in the rubber carousel were investigated through a series of laboratory experiments performed in identical initial conditions. Subsequently, the results of the experimental analysis were compared with the results of the CAE analysis. The experiment scheme is presented in Figure 2. The results were verified applying the finite element method.

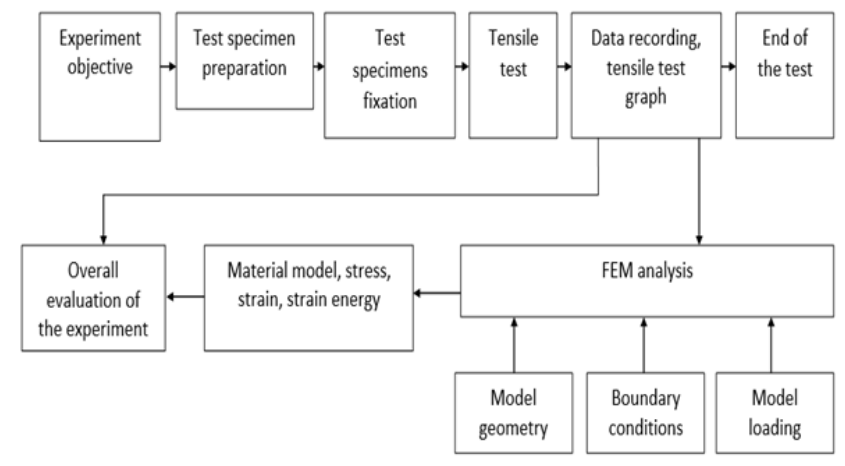

Figure 2. Block diagram of the experiment

\subsection{Creation of the Model}

The numerical stress-strain analysis of the specimen was carried out applying the finite element method in the Creo-Simulate tool. The Structure module of Creo-Simulate facilitates simulation, evaluation, and optimisation of the structural behaviour of the model in the field of statics. The calculations were made applying the geometric element method which is based on the fragmentation of the analysed volume into elements that accurately respect the created 3D model. For this SOLID volumetric model, the used types of 3D elements included Tetra, Brick, and Wedge. The mesh was generated automatically; the mesh of elements was also subjected to certain optimisation in order to obtain a high-quality analysis model. If required, certain manual interventions in this process are possible for the purpose of increasing the quality of the mesh.

\subsection{Testing Device}

The tensile tests were carried out using the tensile testing device Zwick/Roell Z030 (Figure 3.). During the test, the test specimens were exposed to the tensile load at the speed of $100 \mathrm{~mm} / \mathrm{min}$ until the rupture occurred, at the ambient temperature. During the test, a video extensometer (vidoeXtens) was used to measure the elongation [24] of the predefined length of the working section of the test specimen which was marked with white reference lines drawn using a template. Three test specimens were prepared for the test; they were cut out of the conveyor belt in the transversal direction and the basic mechanical properties of these test specimens were determined.

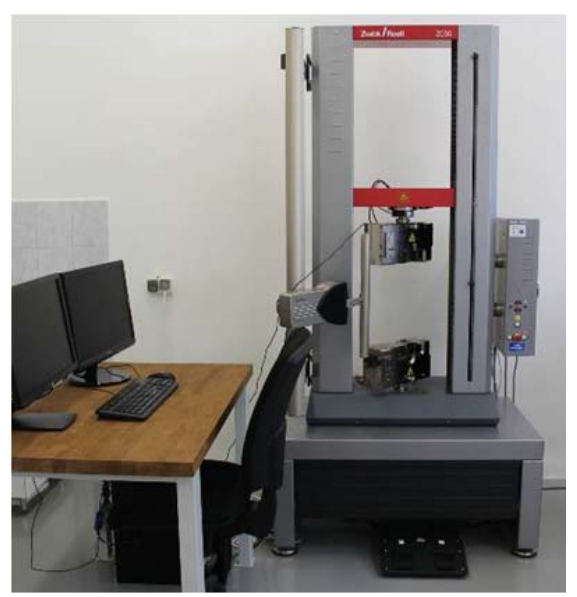

Figure 3. Tensile testing device for measuring the tensile strength of carousels

\section{Theory/Calculation}

\subsection{Physical Fundamentals}

The A-type test specimens were prepared for the tensile tests (Figure 4.). During the test, the test specimen was exposed to the tensile load at the speed of $100 \mathrm{~mm} / \mathrm{min}$ until the rupture occurred, at the ambient temperature. During the test, the video extensometer (vidoeXtens) was used to measure the elongation of the predefined length of the working section of the test specimen which was marked with white reference lines drawn using a template. Three test specimens were cut out of the conveyor belt in the transversal direction and the basic mechanical properties of these test specimens were determined.

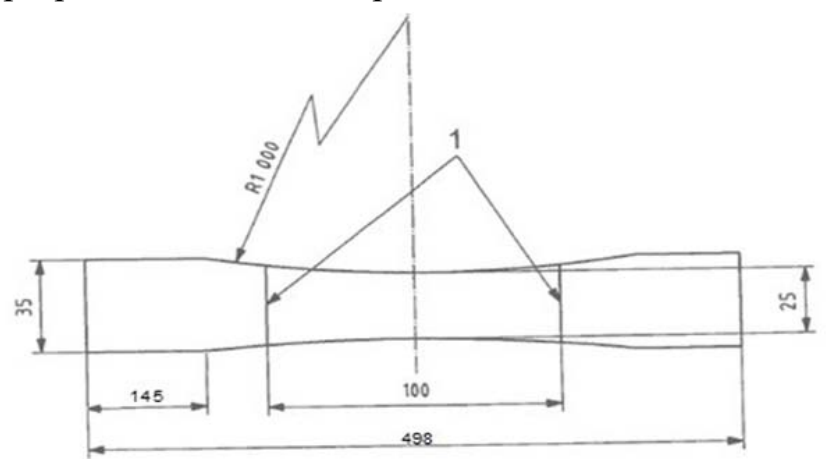

a) Dimensions of specimen, 1 - reference lines

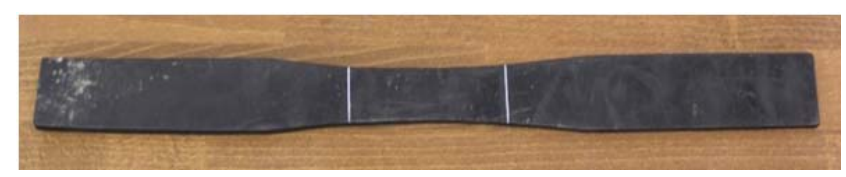

b) Specimen with the marked measured length

Figure 4. A-type test specimen 
In order to identify the tensile strength, the maximum force $F_{r}$, was recorded at the moment of the rupture and then divided by the cross-sectional area of the test specimen. The tensile strength of the belt $R_{s}[\mathrm{MPa}]$ was calculated using the following formula:

$$
R_{S}=\frac{F_{r}}{A_{t}}
$$

where $F_{r}$ is the loading force to which the test specimen was exposed at rupture $[\mathrm{N}]$; and

$A_{t}$ is the cross-sectional area of the working section of the test specimen $\left[\mathrm{mm}^{2}\right]$.

Elongation $\varepsilon[\%]$ is the change in the length of the test specimen at rupture and is calculated using the following formula:

$$
\varepsilon=\frac{L_{2}-L_{1}}{L_{1}} \cdot 100
$$

where $\varepsilon$ is the elongation [\%];

$L_{l}$ is the original measured length [mm], $L_{l}=100$ $\mathrm{mm}$; and

$L_{2}$ is the length measured after the test specimen deformation $[\mathrm{mm}]$.

\section{Results}

The experimental tests were carried out using the specimens of a carousel from light conveyor belts. The purpose of the laboratory experimental research was to identify the basic mechanical properties of rubber carousels and then identify the optimal material model, using the obtained measurement results, while considering the dynamic load of rubber carousels.

\subsection{Experimental Analysis of Mechanical Properties of Rubber Carousels}

Mechanical properties, individual values for 3 tested specimens (no. 2-4), of the tested conveyor belt are listed in Table 1. Test specimen no. 1 was ruptured out of the working section, this means that these results aren't valid and unlisted in Table 1. The maximum force $F_{r}$ was determined, as well as the tensile strength along the whole length of the conveyor belt $f_{s}$, and the elongation at rupture $\varepsilon$. The obtained tensile diagrams documenting the development of the loads to which the test specimens were exposed applying the uniaxial tension are shown in Figure 5. All valid test specimens were ruptured in the working section between the reference lines (Figure 6.).
Table 1. Mechanical properties of rubber carousels

\begin{tabular}{|c|c|c|c|}
\hline Specimen no. & $\boldsymbol{F}_{\boldsymbol{r}}[\mathbf{N}]$ & $\boldsymbol{R}_{\boldsymbol{s}}[\mathbf{M P a}]$ & $\boldsymbol{E}[\mathbf{\%}]$ \\
\hline $\mathbf{2}$ & 1126.2 & 7.94 & 177.7 \\
\hline $\mathbf{3}$ & 1113.7 & 7.57 & 168.2 \\
\hline $\mathbf{4}$ & 1227.2 & 8.51 & 187.5 \\
\hline $\begin{array}{c}\text { Arithmetic } \\
\text { mean }\end{array}$ & 1155.7 & 8 & 177.8 \\
\hline
\end{tabular}

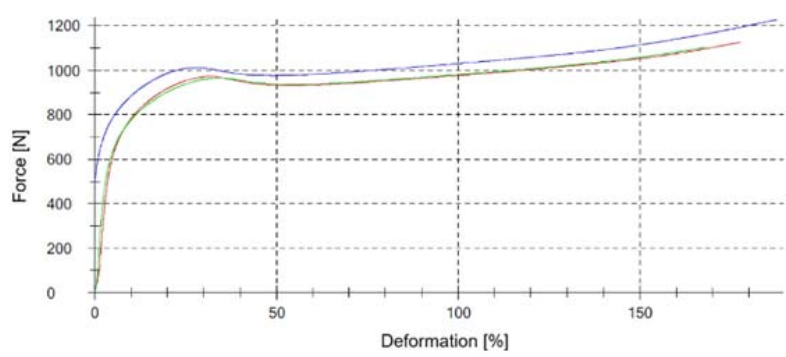

Figure 5. Tensile diagrams (Specimen 2 - red curve; Specimen 3 - green curve; Specimen 4 -blue curve)

$2 \quad 2$

Figure 6. Test specimen (blade) after the test

\subsection{CAE Analysis and Implementation of the Hyperelastic Material Laws in the Creo- Simulate}

The numerical stress-strain analysis of the specimen was carried out applying the finite element method in the Creo-Simulate tool. The Structure module of Creo-Simulate facilitates simulation, evaluation, and optimisation of the structural behaviour of the model in the field of statics. The calculations were made applying the geometric element method which is based on the fragmentation of the analysed volume into elements that accurately respect the created 3D model. For this SOLID volumetric model, the used types of 3D elements included Bricks. The mesh was generated automatically; the mesh of elements was also subjected to certain optimisation in order to obtain a high-quality analysis model. If required, certain manual interventions in this process are possible for the purpose of increasing the quality of the mesh. In our case, we used the Mapped Mesh Control (Figure 7.).

In order to achieve the required accuracy of the calculation results, the P-adaptive meshing was applied; this method adjusts the polynomial order of the mesh. For the purpose of ensuring high-quality results, the adaptive finite element methods use an extension based on the theory of errors modifying the mesh of finite elements in the solving process in order to identify the approximated solution within certain limits from the "real" solution of a continuous problem. In practice, this means that during the calculation, the calculated values (of strain, strain energy, and the quadratic mean of stress) are compared. The edges of individual elements are 
divided into identical numbers of parts and in individual points this verification is carried out. The calculated values in the $n^{\text {th }}$ iteration were compared with the values from the previous iteration until the predefined accuracy of convergence is achieved. Otherwise, the degree of the polynomial gradually increases to the maximum of 9. The predefined value of the degree of the polynomial was 6 and the calculation accuracy (convergence) was $10 \%$ while these values may be modified as desired (Figure 7.).
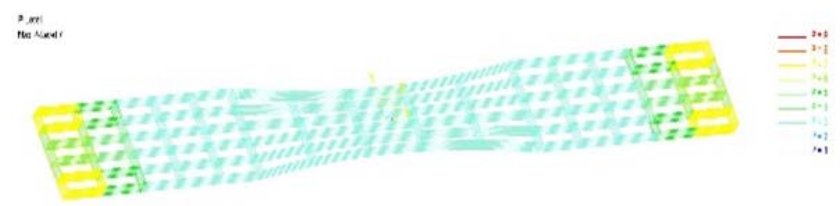

\section{Figure 7. FEM model with mapped mesh control and polynomial order of the mesh}

Subsequently, the non-linear static analysis of large deformations of the specimen model was applied to assess the stress-strain processes running while the specimen was exposed to the tensile load from 0 to $200 \mathrm{~mm}$ (Figure 8). One figure corresponds to the stress observed while the specimen was stretched in approximately $20 \mathrm{~mm}$. The results of the numerical analysis proved concordance with the mechanical test where the tensile strength of the used material was 7.5 MPa. This material model may later be used in real operations to analyse conveyor belts made of this particular material.

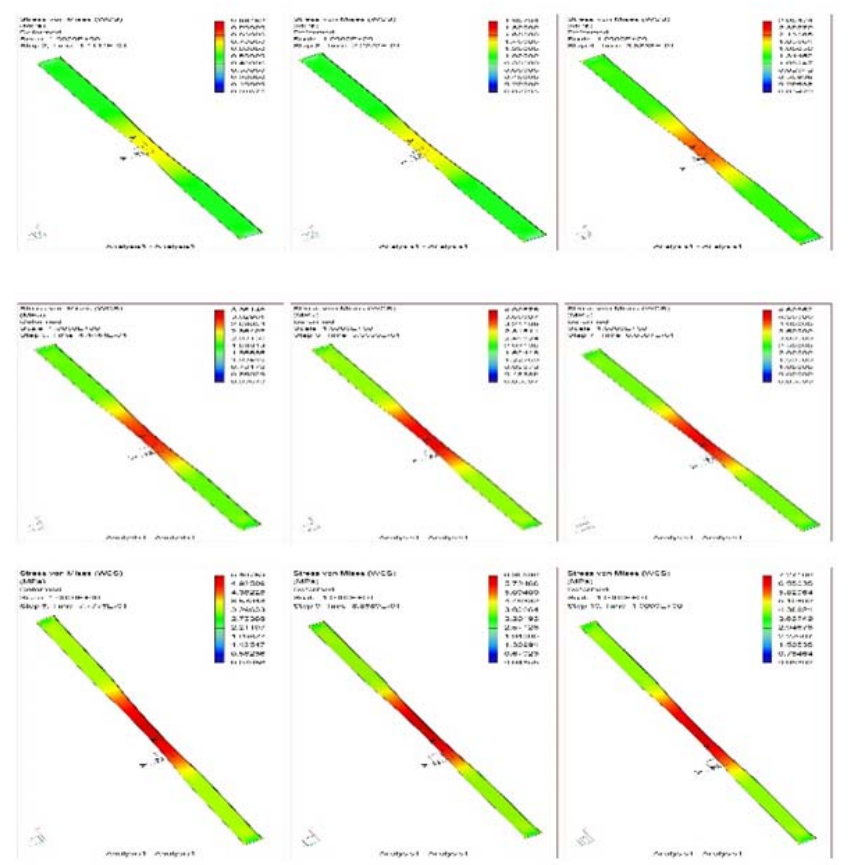

Figure 8. Stresses observed while the sample was gradually exposed to the load

The Structure module contains the library of commonly used materials which facilitates assigning the material properties. Materials may be isotropic, orthotropic, or transversely isotropic. Assigning certain material enables conducting certain adjustments to the generated mesh. In the usual technical practice, the calculations are carried out in the area of linear tasks, i.e., in the area of elastic deformation or in the area of validity of the Hooke's law. As for the analysed specimen, it was an isotropic material with the Stress-Strain Response Hyperelastic characteristics obtained through mechanical tensile tests.

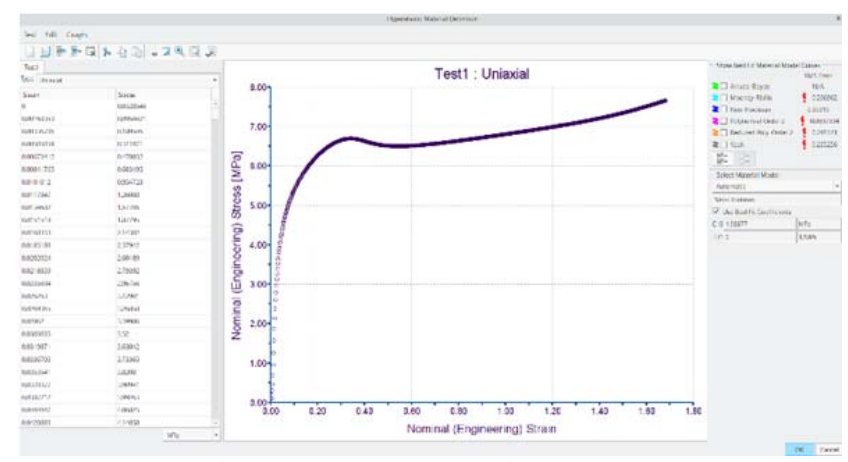

Figure 9. Hyperelastic material definition

The results of the tensile test were transformed into the Creo-Simulate environment in order to select the most optimal mathematical model of the used material for the next numerical analysis. Out of several material models (Arruda-Boyce, MooneyRivlin, Neo-Hookean, Polynomial Order 2, Reduced Poly. Order 2, Yeoh), the software chose the NeoHookean as the most suitable one for the used specimen (Figure 9.).

\section{Conclusions}

A rubber carousel is a component of carousel conveyor belts which functions as the main carrier of the goods - baggage.

The methods of improving utility properties of rubber carousels include the application of the numerical experimental stress-strain analysis. The application of the finite element method in the CreoSimulate software, using the Structure module, facilitates simulation, evaluation, and optimisation of the energy of the impacting baggage or loads. The main outputs of the article include:

- Creation of the model intended for solving complicated tasks and facilitating better understanding of carousel behaviour under such dynamic load while simulating real conditions;

- Verification of physical and mechanical properties of rubber carousels. The difference between the FEM results and the experimentally identified correlation between the tension and the stress and strain was $1.8 \%$;

- Verification of the values of the modelled maximum stress relative to the calculated stress, depending on the effects of the dynamic force. 
The results obtained by modelling are important for manufacturers of rubber carousels as well as users of conveyors intended for the manipulation with baggage and various goods at airports. Creation of material models facilitates the assessment of the accuracy of the choice of particular rubber carousel structures for particular operating conditions. Manufacturers may apply the CAE analysis when designing and developing novel carousel structures with higher resistance to damage. The main advantage of this method is the short-lasting execution of parametric studies regarding the optimisation of rubber carousel structures.

\section{Acknowledgements}

This research was funded by the Slovak Research and Development Agency under the contract No. APVV-180248 titled „Smart Belt Conveyors “ and by project VEGA 1/0429/18 „Experimental research of stress-strain states of rubber composites used in the mining and processing of raw materials".

\section{References}

[1]. Bradley, A. L. (2010). The independent airport planning manual. Elsevier.

[2]. Lenior, O. N. M. (2012). Airport baggage handlingwhere do human factors fit in the challenges that airports put on a baggage system?. Work, 41(Supplement 1), 5899-5904.

[3]. Barth, T. (2013). Optimal assignment of incoming flights to baggage carousels at airports. DTU Management Engineering Report, (4.2013).

[4]. Hardygóra, M., Komander, H., Bajda, M., \& Komander, G. (2010). Conveyor belt with increased operational wear resistance. Transport\&Logistics, 19, 26-32.

[5]. Andrejiova, M., Grincova, A., \& Marasova, D. (2018). Failure analysis of rubber composites under dynamic impact loading by logistic regression. Engineering Failure Analysis, 84, 311319.

[6]. Grincova, A., Berezny, S., \& Marasova, D. (2009). Regression model creation based on experimental tests of conveyor belts against belt rips resistance. Acta Montanistica Slovaca, 14(1), 113120.

[7]. Ambriško, L., \& Marasová, D. (2017). Evaluation the quality of rubber composites using the DOE method. Calitatea, 18(158), 60.

[8]. Bindzár, P., \& Grinčová, A. (2007). Contribution to the modeling of elements with hyperelastic properties (in Slovak). Transport \& Logistics, 7, 1-4.

[9]. Šaderová, J. (2018). Laboratory Research Of A Conveyor Belts With A Textile Carcass For Mine Conveying. In 18th International Multidisciplinary Scientific GeoConferences SGEM 2018 (pp. 537-544).
[10]. Grincova, A., Andrejiova, M., Marasova, D., \& Khouri, S. (2019). Measurement and determination of the absorbed impact energy for conveyor belts of various structures under impact loading. Measurement, 131, 362-371.

[11]. YAZICI, M., KAPUCU, O. A., KASIM, H., \& Yücel, C. A. N. (2014). Experimental Investigation on Fatigue Life of Cord-Rubber Composites. Avrupa Bilim ve Teknoloji Dergisi, (Özel Sayı-Special Issue), 16-21.

[12]. Bishop, N. W., \& Sherratt, F. (2000). Finite element based fatigue calculations. NAFEMS.

[13]. Long, M. C., Kisielewski, R. W., Richardson, D. C., \& Schroeder, L. W. (2001). An experimental technique for determining biaxial fatigue lifetimes in biomedical elastomers. International journal of fatigue, 23(10), 911-916.

[14]. Dai, Y., Song, X., Xue, D., Zhou, J., \& Ding, F. (2005). Predetermination of initial crack and fracture surface of the engine suspending bearing. Nongye Jixie Xuebao(Transactions of the Chinese Society of Agricultural Machinery), 36(10), 23-25.

[15]. Wang, L., Lu, Z., \& Ichiro, H. (2002). Finite element modeling of rubber mount and its static elastic characteristic simulation. Qiche Gongcheng/Automotive Engineering, 24(6).

[16]. Diani, J., Brieu, M., \& Gilormini, P. (2006). Observation and modeling of the anisotropic viscohyperelastic behavior of a rubberlike material. International Journal of Solids and Structures, 43(10), 3044-3056.

[17]. Mazurkiewicz, D. (2009). Problems of numerical simulation of stress and strain in the area of the adhesive-bonded joint of a conveyor belt. Archives of Civil and Mechanical Engineering, 9(2), 75-91.

[18]. Zhang, X., \& Zhao, G. (2015). Overview of experimental studies on strength problem of rubber material. 5th International Conference on Advanced Engineering Materials and Technology AEMT 2015, 13-22.

[19]. Seichter, S., Archodoulaki, V. M., Koch, T., Holzner, A., \& Wondracek, A. (2017). Investigation of different influences on the fatigue behaviour of industrial rubbers. Polymer Testing, 59, 99-106.

[20]. Čerňan, J., Semrád, K., Draganová, K., \& Cúttová, M. (2019). Fatigue stress analysis of the DV-2 engine turbine disk. Aircraft Engineering and Aerospace Technology.

[21]. Martins, P. A. L. S., Natal Jorge, R. M., \& Ferreira, A. J. M. (2006). A comparative study of several material models for prediction of hyperelastic properties: Application to silicone-rubber and soft tissues. Strain, 42(3), 135-147.

[22]. Zhao, J., Li, Q., \& Shen, X. (2008). Finite element analysis and structure optimization for improving the fatigue life of rubber mounts. Journal of Macromolecular Science, Part A, 45(6), 479-484.

[23]. Mapelli, C., \& Barella, S. (2007). Failure analysis of a ball transfer unit. Engineering Failure Analysis, 14(4), 579-587.

[24]. Ambriško, L., \& Pešek, L. (2014). The stretch zone of automotive steel sheets. Sadhana, 39(2), 525-530. 